Article

\title{
The 1730 Great Metropolitan Chile Earthquake and Tsunami Commemoration: Joint Efforts to Increase the Country's Awareness
}

\author{
Natalia Zamora ${ }^{1,2, *}$, Alejandra Gubler ${ }^{1}$, Víctor Orellana ${ }^{3}$, Jorge León ${ }^{1,4}$, Alejandro Urrutia ${ }^{1}$, \\ Matías Carvajal 2,5, Marco Cisternas 2,6 , Patricio Catalán 1,7 D, Patricio Winckler 1,8,9 (D), \\ Rodrigo Cienfuegos 1,10, Cristóbal Karich ${ }^{1}$, Stefan Vogel ${ }^{1}$, José Galaz ${ }^{10,11}$, \\ Sebastián Pereira ${ }^{11}$ and Celeste Bertin 11,12 \\ 1 Research Center for Integrated Disaster Risk Management (CIGIDEN), ANID/FONDAP/15110017, \\ Santiago 7820436, Chile; alejandra.gubler@alumnos.usm.cl (A.G.); jorge.leon@usm.cl (J.L.); \\ alejandro.urrutia@cigiden.cl (A.U.); patricio.catalan@usm.cl (P.C.); patricio.winckler@uv.cl (P.W.); \\ director@cigiden.cl (R.C.); cristobalkarich@gmail.com (C.K.); stefan.vogel@cigiden.cl (S.V.) \\ 2 Millennium Nucleus The Seismic Cycle Along Subduction Zones (CYCLO), Chile; \\ matias.carvajal.ramirez@gmail.com (M.C.); marco.cisternas@pucv.cl (M.C.) \\ 3 Fundación Proyecta Memoria, Santiago 9480072, Chile; vorellana@proyectamemoria.cl \\ 4 Departamento de Arquitectura, Universidad Técnica Federico Santa María, Valparaíso 2390123, Chile \\ 5 Programa de Doctorado en Ciencias Geológicas, Facultad de Ciencias Químicas, \\ Universidad de Concepción, Concepción 4070386, Chile \\ 6 Instituto de Geografía, Pontificia Universidad Católica de Valparaíso, Valparaíso 2340000, Chile \\ 7 Departamento de Obras Civiles, Universidad Técnica Federico Santa María, Valparaíso 2390123, Chile \\ 8 Escuela de Ingeniería Civil Oceánica, Universidad de Valparaíso, Valparaíso 2362844, Chile \\ 9 Centro de Observación Marino para estudios de Riesgos del Ambiente Costero (COSTAR-UV), \\ Valparaíso 2362844, Chile \\ 10 Departamento de Ingeniería Hidráulica y Ambiental, Pontificia Universidad Católica de Chile, \\ Santiago 7820436, Chile; jdgalazm@gmail.com \\ 11 Inria Chile, Santiago 7550268, Chile; sebastian.pereira@inria.cl (S.P.); celbertin@gmail.com (C.B.) \\ 12 Equifax, Santiago 7550647, Chile \\ * Correspondence: natalia.zamora@cigiden.cl
}

Received: 22 April 2020; Accepted: 20 May 2020 ; Published: 24 June 2020

\begin{abstract}
On 8 July 1730, a great earthquake struck metropolitan Chile, causing extensive damage $1000 \mathrm{~km}$ along the country and focused in Valparaíso. Due to the date of occurrence of this event, large uncertainties about the earthquake's magnitude have been discussed among the scientific community, and the earthquake and tsunami have remained unknown for most of the population. The purpose of this paper is to describe joint efforts undertaken by organizations, academia, and authorities to rescue the forgotten memory of an event that occurred almost three centuries ago and that may be repeated in the near future. In line with the Sendai Framework, we focus on one of the four priorities for action, which is to understand disaster risk, with the premise that the memory activation and raising awareness can save lives in the future. We designed outreach strategies to communicate this knowledge to the community in a participatory way. The latter involves scientific talks, earthquake simulators, tsunami projection mapping on relief scaled models (mock-up), and a public debate including the participation of academia, politicians, authorities, and the local community. The emulation of such activities and the constant work of regional and national authorities, academia, and non-governmental organizations dealing with risk mitigation encourage involving the community to build safer cities against the tsunami hazard.
\end{abstract}

Keywords: tsunami threat and risk; outreach; awareness; 1730 tsunami; Valparaíso; Chile 


\section{Introduction}

The metropolitan area of Chile, including the main harbor city of Valparaíso, have historically suffered several large earthquakes (Figure 1). Since the 18th Century, at least four interplate earthquakes greater than Mw 8.0 (1730, 1822, 1906, and 1985 events) have been generated in this area [1]. The accumulated death toll, caused by the earthquakes and secondary effects (e.g., tsunami), for these four events was 4830 casualties [2]. More recently, two large earthquakes in the immediate neighborhood affected Valparaíso, in the south in 2010 (Mw 8.8) and in the north in 2015 (Mw 8.3).


Figure 1. Left panel: Map showing the extent of maximum tsunami inundation according to the Tsunami Inundation Chart for Valparaíso and Viña del Mar [3]. Yellow triangles show the data of the tsunami inundation extent based on historical records along Valparaíso. P1 stands for the location of La Matriz church where historical records indicated the maximum wave height of $9 \mathrm{~m}$. P2 stands for the location of the Augustinian convent where historical records reported the maximum wave height of $11 \mathrm{~m}$. P3 stands for Mercedarian convent where the maximum wave height reported in historical records was $9 \mathrm{~m}[1,4]$. The contour line of $30 \mathrm{~m}$ above sea level (m.a.s.l.) is shown in black. The numbers refer to the schools where talks were given. The right panel shows the location of selected coastal cities in Chile. Blue circles stand for approximated earthquake epicenters greater than Mw 8.0 in the year 1500-2020 (the year of occurrence is given for selected events). The earthquake locations are based on ComCat [5].

On the morning of 8 July 1730 at 4:30 a.m. local time, an earthquake struck along the Valparaíso area, causing damage for at least $1000 \mathrm{~km}$ of the coast and triggering a Pacific-wide tsunami that affected a large area of Chile and was even recorded in Japan [1,6]. This event is considered as the largest earthquake that has ruptured along the Valparaíso seismo-tectonic segment in the historical period [7]. The work based on historical records, estimated the magnitude of this earthquake as surface-wave magnitude Ms 8.5 and 9.0 based on the tsunami effects [8]. A recent study, based on the tsunami effects, suggested a moment magnitude between Mw 9.1 and 9.3 [1].

The historical letters sent by bishops and governors to the King of Spain, Felipe V, described the impact of the event. According to these historical documents, the work in [7] described the damage caused by the earthquake that completely destroyed the village of Valparaíso. This earthquake was felt in most of the country, also causing damage between Copiapó and Concepción [4] and even beyond the Andes, in the Argentinian city of Mendoza.

In particular, in Valparaíso, tsunami heights (herein, as the vertical distance between the maximum inferred flood level and the mean sea level) were in the order of $10 \mathrm{~m} \mathrm{[1]}$. Descriptions found in historical records preserved from the religious convents located in Valparaíso (Figures 1 and 2) and 
Penco (Concepción) indicated that the 1730 tsunami flooded inland a distance between 350 and $850 \mathrm{~m}$, respectively. These buildings were located about $11 \mathrm{~m}$ and $9 \mathrm{~m}$ above sea level in Valparaíso and Penco, respectively [1], on sites that are today inland of the official tsunami inundation limits.

a)

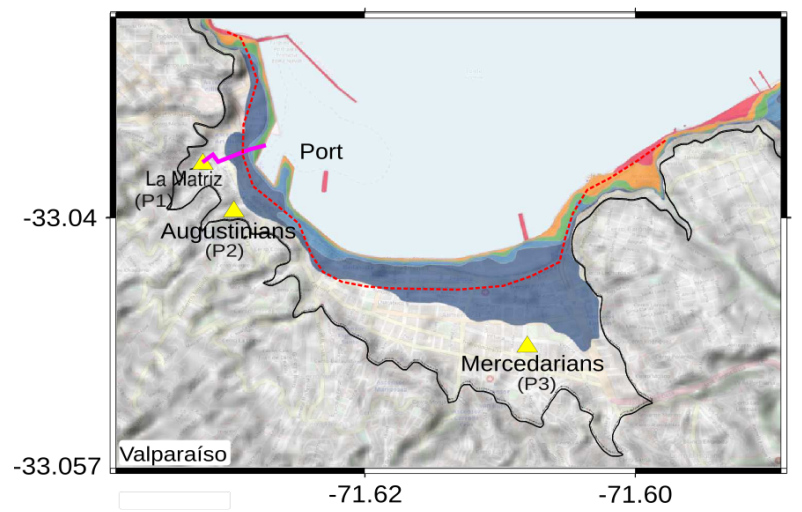

b)

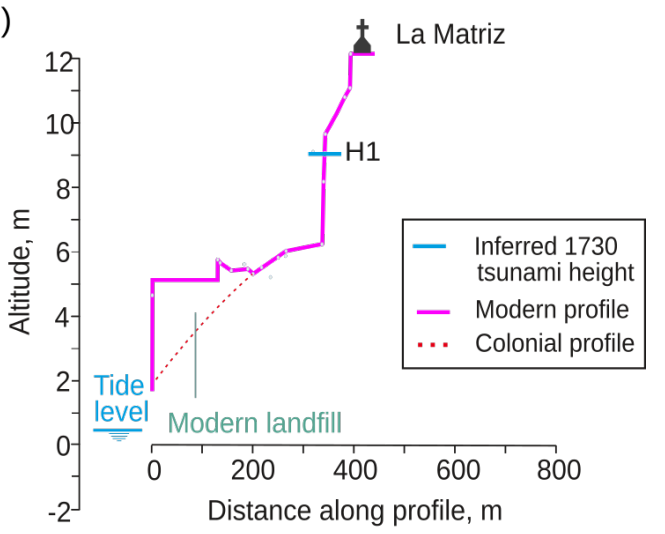

c)



Figure 2. (a) Map showing the extent of maximum tsunami inundation and flow depths according to the Tsunami Inundation Chart for Valparaíso and Viña del Mar (CITSU, in Spanish) according to [3], as well as the location of the maximum tsunami height reported in historical records (yellow triangles) shown also in Figure 1; the profile line is shown in magenta, and the colonial coastal line [1] is shown in red. (b) The topographic profile along La Matriz (P1), where tsunami records suggested a $9 \mathrm{~m}$ tsunami height (light blue line), modified from [1]. (c) Photo of La Matriz Church (provided by Google Maps [9]), where light blue lines indicate the estimated position range of the maximum tsunami height recorded for the 1730 event and the red arrow shows where a plate was supposed to be located (refer also to the first section of Supplementary Material 1).

Although the Chilean population has experienced several earthquakes that have changed their perception of risk $[10,11]$, knowledge of potential mega-earthquakes and their possible effects in the region may not be well recognized yet [11]. This is particularly true for the Valparaíso area owing to several aspects that have helped in establishing an erroneous local narrative among its residents. It is often argued that no tsunamis can occur in the area, because the Valparaíso bay is too deep and naturally protected by its shape. The origin of this false perception is uncertain, but several factors can be inferred to explain its deep-rooted belief among the population. First and foremost, Valparaíso has not been affected by destructive tsunamis in its recent history, despite the large number of earthquakes that have occurred. Most notably, the two most recent local events were conspicuous because of the minor associated tsunami. The 1906 earthquake [12] is well remembered due to the sheer level of destruction of the city, but no records of the tsunami exist, at least in the collective memory. Similarly, for the 1985 event, despite the tsunami reaching $1.5 \mathrm{~m}$ at the tide gauge in Valparaíso, it did not cause damage. Even regionally, large magnitude events have not caused noticeable effects in Valparaíso, such 
as in the 1960 Valdivia, 2010 Maule, and 2015 Illapel earthquakes and tsunamis. Moreover, the latter did cause damage in the nearby town of Concón $(\approx 20 \mathrm{~km}$ north of Valparaíso), which could be further reinforcing the notion of no tsunami hazard in the area.

The reasons for these behaviors are multifold. First, the 1906 and 1985 earthquakes ruptured way too deep along the megathrust zone to generate large tsunamis [12]. Second, the low areas both in Valparaíso and Viña del Mar are located slightly above sea level $(\approx 4 \mathrm{~m})$. The 1906 and 1985 events occurred during moderate tidal levels, all between 0 and $0.5 \mathrm{~m}$, as estimated here with harmonic analysis. Hence, tsunami waves need to exceed the tide range $(1.9 \mathrm{~m})$ to become noticeable, and even so, they may not cause damage to infrastructure. Lastly, ongoing research suggests that the multiple bay system transfers more tsunami energy to nearby bays such as Concón, while Valparaíso bay experiences less energetic behavior $[13,14]$.

This notion, that the Valparaíso bay is not commonly subjected to tsunamis, contrasts the reality. Actually, from a technical standpoint, the Valparaíso bay has seen several tsunamis in the intervening years, as a consequence of very smaller seismic events that occurred every few years (e.g., the small tsunami associated with the Mw 6.9 Valparaíso earthquake in 2017). However, most of these tsunamis have only been noticed by instruments (tide gauges), but not by people due to their small size. This is a problem, enhancing the perception of the population of metropolitan Chile who are used to feeling earthquakes on a regular basis, but not being affected by any associated tsunami. The consequences of this situation could be severe if the area is hit by earthquakes occurring along the outer rise, or by a special class of earthquakes, known as tsunami earthquakes [15]. The tsunami earthquakes that occur in the shallowest portion of the megathrust zone cause very slight shaking, but are accompanied by large tsunamis $[16,17]$. Therefore, if one of these events occurs in Valparaíso, people may not evacuate because of (1) their false perception of tsunami immunity and because (2) their natural association between the intensity of shaking and tsunami size. Hence, eradicating these misconceptions is of utmost importance to saving lives in a future event.

In this paper, we describe the activities and outreach material developed to do away with these misconceptions through transferring findings about earthquakes and tsunamis and the effects of the 1730 event in the communities of Valparaíso and Vinã del Mar, which together hold a population of over 600,000 people. In this work, Section 2 describes the role of education for understanding the threat and risk; Section 3 presents several projects and materials developed as part of the outreach programs and particularly for the commemoration; Section 4 describes the outcomes of the commemoration day; and Section 5 sets future perspectives of this joint work to mitigate risk through transferring scientific knowledge to the community.

\section{Understanding the Risk}

The joint efforts to commemorate the 1730 earthquake and tsunami arose from the need to increase awareness among the local Valparaíso community about the tsunamis that may recur. Spurred by new scientific evidence [1,4], the non-profit Proyecta Memoria Foundation, together with research centers and authorities, organized several activities to commemorate the anniversary of the 1730 event. The goal was to preserve the memory of past disasters as an element of education and preparation for future disasters, based on the notion that memory activation and awareness can save lives. The premise behind this is that preparedness against future events is more effective when education and awareness activities are built over experiential disaster memories (e.g., [18]).

New knowledge about this earthquake and associated tsunami is already changing the way authorities and technical institutions are undertaking the earthquake and tsunami risk along the coast of the Valparaíso region. For instance, the new evidence has led to updating the inundation maps developed by the Hydrographic and Oceanographic Service of the Chilean Navy (SHOA). The earlier versions of its maps were based on the 1906 Valparaíso earthquake, a deeper than average earthquake that triggered a minor tsunami [8]. The hazard posed by an earthquake and tsunami like the one in 1730 supposes a greater risk due not only to the increased hazard, but also to the high level of exposure 
and enhanced coastal development with homes, high rise buildings, commerce, services, and port infrastructure. Moreover, the area is a renowned hotspot for tourism, thriving during summer with beach goers from elsewhere in the country and other Latin American countries, with possibly limited education on tsunami threats and how to respond to these.

In this sense, the dissemination of these historical events to the local community through awareness, education, and commemoration activities of the 1730 earthquake is of great importance. The ultimate goal of this series of activities is to build a bridge between scientific knowledge and communities exposed to risk. How can this be conducted has been widely explored [19-22]. In particular, the work in [21] described the contributions of education in the National Tsunami Hazard Mitigation Program of the United States, where education has been identified at the top of the mitigation strategic planning area for resilient communities.

In Chile, national organizations have been traditionally in charge of developing risk mitigation measures and public policies, and academia and other organizations have also played a crucial role in framing the gaps and providing technical information. Furthermore, dissemination and education about the tsunami hazard have been commonly addressed by national authorities [23]. In the aftermath of the 2010 event, a shift in the way of thinking has been more noticeable, whereby a closer relationship and synergy between authorities and academia has led to a strengthening of capabilities and procedures; for example, by enhancing the tsunami early warning systems [24] and assessing the impact of a tsunami worst-case scenario in the region [25]. Transferring this knowledge to the local community can mitigate future disasters by increasing awareness and risk perception $[10,11]$. Hence, a series of activities were planned and co-organized by authorities such as the National Emergency Office of the Ministry of the Interior and Public Security (ONEMI, in Spanish), SHOA, and the Ministry of Education; academic and research centers such as the Research Center for Integrated Disaster Risk Management (CIGIDEN, in Spanish) and The Sesimic Cycle Along Subduction Zones Millennium Nucleus (CYCLO); NGOs such as Proyecta Memoria; and local authorities (municipality, police department). Notably, the leading role was undertaken by Proyecta Memoria and CIGIDEN, with the support of the authorities. This joint effort allowed a more effective coordination and helped to broaden the scope of the activities planned.

\section{Materials and Methods}

Commemorations are public activities in which individuals and organizations are invited to learn, remember, and share reflections on how the tragic experiences of past disasters can become positive learning experiences for current and future generations [18]. Activities can consider a wide range, including educational, cultural, and urban intervention. These must be supported by historical and scientific evidence to support their validity.

For this, the main activities developed started with material that could be easily adapted for different members of the public, such as talks to students, educational material for different ages, a mobile earthquake simulator (Figure 3), interactive activities, brochures, handouts, and projection mapping tsunami inundation models. The local agents of ONEMI have a channeling role in these kinds of events as an entity in charge of emergencies at the regional and national levels. In this case, ONEMI was in charge of the earthquake simulator and disseminated information for a community drill issued for 30 September 2019, where at least 110,000 people participated in Valparaíso and Viña del Mar. The commemoration ended with a round table discussion (public debate) where the policy paper "Vertical evacuation as a measure to mitigate the risk of tsunamis in Chile" [26] was presented and discussed with invited Chilean authorities.

In the following subsections, we show the education material developed for such activities with the community. Furthermore, we describe the scientific results that shed light on the need for vertical evacuation structures. The latter was key data for the policy paper and round table discussions presented as part of the results of the commemoration activities. 



Figure 3. Setup at La Matriz square and the earthquake simulator brought by ONEMI.

\subsection{Outreach Material for Scientific Exhibitions}

Several materials were developed for the different activities throughout the country. Particularly, CIGIDEN used two different tools to show to the public the physical processes of tsunami generation, propagation, and inundation. The first one was TsunamiLab (http://tsunamilab.cl, last accessed 10 April 2020), which is an interactive platform for simulation and visualization of tsunamis, based on geophysical models (Figure 4). It allows the user to create virtual tsunamis or recreate historical tsunamis and watch their impact in various digital and augmented reality formats. There are four presentation formats: web application, hologram, touch screen, and the pool format. In this case, CIGIDEN employed the pool format; based on cameras and projectors, the pool allows children and adults to interact using both hand and special finger movements. In this way, a tsunami can be generated anywhere over the ocean, propagating over the ocean basins, and using the time counter, the tsunami time of arrival at different places can be seen. This allows the instructor to teach and involve several children simultaneously, while being entertaining and clear for the public.
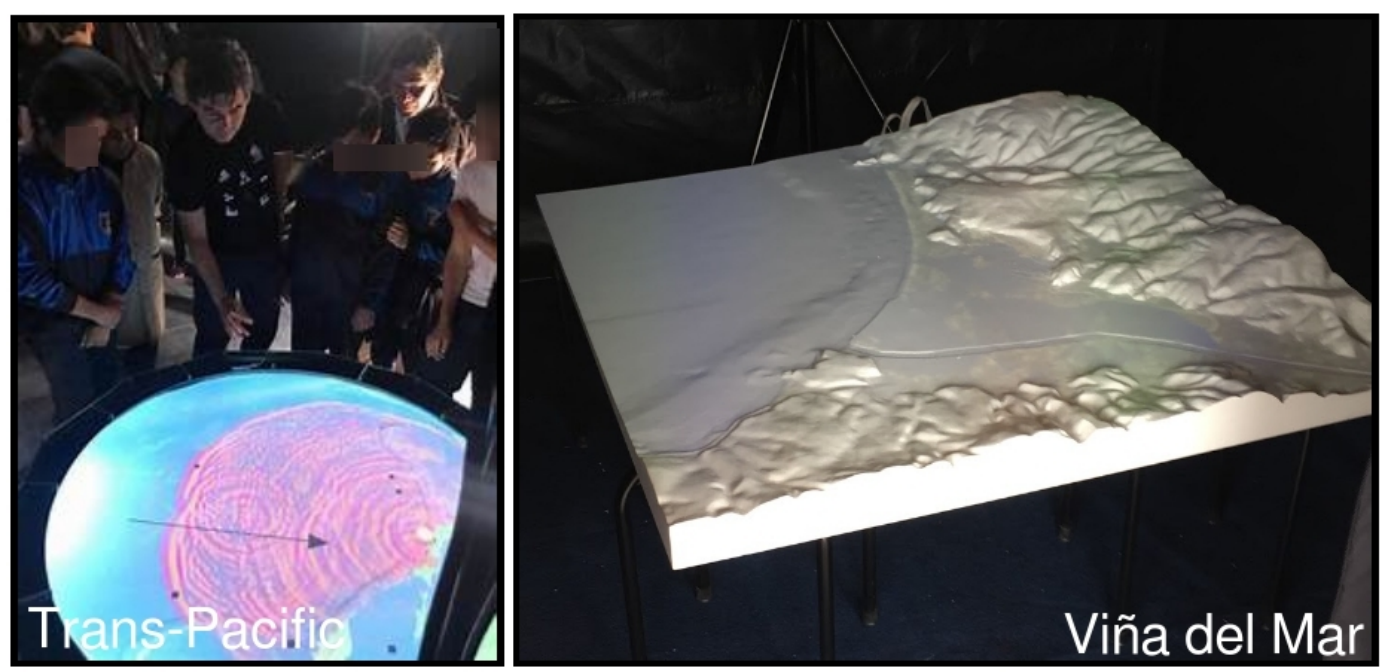

Figure 4. TsunamiLab simulation (left panel) and projection mapping of the tsunami inundation model on the Viña del Mar scaled relief mock-up, where numerical simulations are projected (right panel).

The second tool is a tsunami inundation simulation on a 3D scaled relief model. This mock-up is made of wood, carved by a computer numerical control (CNC) machine, following a high resolution surface model, and then painted white, as shown in (Figure 4). To date, CIGIDEN has developed mock-ups for eight cities for tsunami inundation: Valparaíso, Viña del Mar, Talcahuano, Chañaral, Iquique, Antofagasta, Constitución, and Cartagena. Additionally, there are videos of tsunami 
inundation, floods (e.g., La Chimba and Chañaral flood), and volcanic eruptions (e.g., Chaitén Volcano), which can also be projected on these kinds of models.

In order to depict the impact of the 1730 event in the Valparaíso region, tsunami propagation and inundation were modeled using the well-known tsunami modeling software Geoclaw [27,28]. The modeled earthquake scenario was obtained from [1], with an estimated moment magnitude between Mw 9.1 and Mw 9.3. High resolution topography and bathymetry were used, and tsunami wave heights and flow depths for the finest grid were stored every $10 \mathrm{~s}$ in order to generate high resolution videos to be projected on the Valparaíso and Viña del Mar mock-ups, as shown in (Figure 4). The maximum tsunami flow depth for Valparaíso and Viña del Mar obtained from the simulation are shown in Figure 5. Based on numerical simulation of an expected worst case scenario, we showed the potential threat of an earthquake similar to the one of 1730 [1], with maximum flow depths of $12 \mathrm{~m}$ and $18 \mathrm{~m}$ on the lower elevations of Valparaíso and Viña del Mar, respectively (Figure 5). The aforementioned videos and the parameters used in the simulation are described in Supplementary Material 2.

The projection mapping of tsunami inundation allowed students and the general public to understand the tsunami process and the extent of inundation in different cities around the country. In Table S2, CIGIDEN's outreach activities related to tsunami risk during 2019 are summarized, reaching approximately 30,400 visitors throughout the country. In particular, for this event, the simulations shown in Figure 5 were used for projection over the scaled relief mock-ups (Figure 6). They allowed the participants to envision the extent of the inundation in Valparaíso and Viña del Mar.



Figure 5. Resulting maximum wave heights in Viña del Mar (left panel) and along the coastal city of Valparaíso (right panel). The seismic source used as the initial condition was based on [1]. Red points stand for the locations of schools shown in Figure 1. 

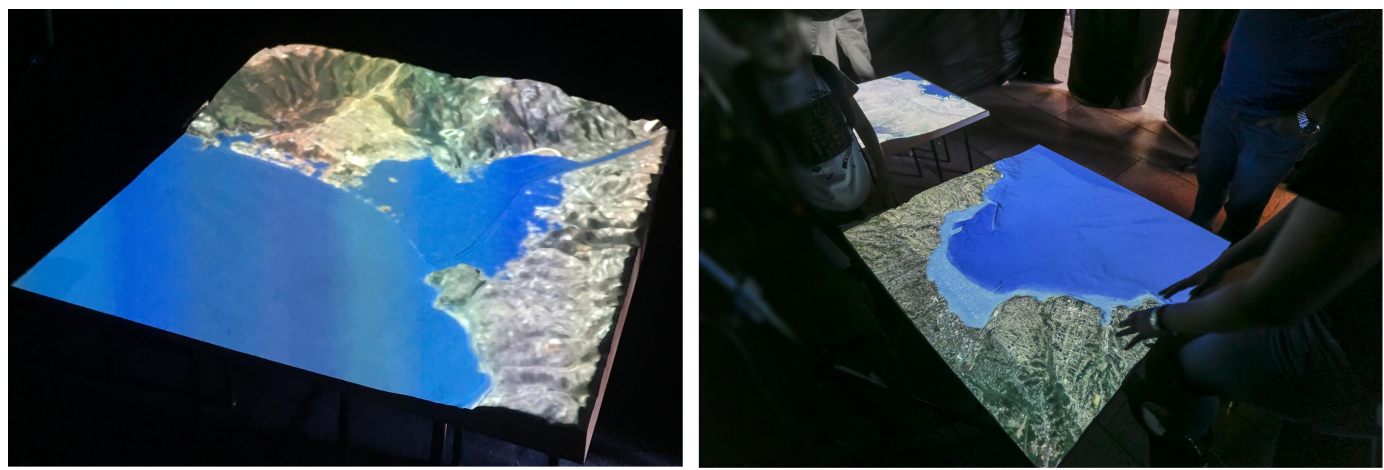

Figure 6. Projection mapping of tsunami inundation on scaled relief models (mock-ups) for Viña del Mar (left panel) and Valparaíso (right panel). Refer to videos 1 and 2 that can be accessed in Supplementary Material.

\subsection{Tsunami Evacuation Simulation Using Agent Based Models in Viña del Mar}

Viña del Mar's downtown elevation is less than $10 \mathrm{~m}$ above sea level (Figure 6) and concentrates about $10 \%$ of the resident population of the county, reaching approximately 35,000 inhabitants for this area [29]. During the summers and long weekends, Viña del Mar's downtown also holds a great variation of floating population, because it receives a large amount of tourists and seasonal visitors. The Statistics National Institute (INE, in Spanish ) reports [30] 200,000 overnight stays in tourist accommodations during the summer tourist season in Metropolitan Valparaíso, including the coastal cities of Valparaíso, Viña del Mar, and Concón, corresponding to an increment of $30 \%$ of the inhabitants of these three cities.

According to the web map services of ONEMI (https://www.onemi.gov.cl/visor-chilepreparado/ accessed on 12 April 2020.), in the downtown of Viña del Mar, there are 10 established security areas to gather people in case of a tsunami, all of them located over 30 m.a.s.l., and 25 evacuation routes are recommended, some of them having paths longer than $2.5 \mathrm{~km}$ from the origin to the assembly areas, as shown in (Figure 7).

Simulations of the downtown's pedestrian tsunami evacuation [31] were done using an agent-based model developed with the PARI-AGENT software, coupling evacuation and tsunami flooding parameters [32]. The tsunami inundation was previously modeled with the aid of STOC-ML software [33], using a worst-case earthquake scenario similar to the 1730 event. Results obtained showed that the estimated tsunami arrival time was about $15 \mathrm{~min}$, and the maximum flow depth was $5 \mathrm{~m}$. For the agent-based model, two population scenarios were simulated: night-time with 28,296 agents and the rush-hour case (53,743, [34]), located in the yellow area in (Figure 7). Four shelters were located in safe zones (the locations of the shelters were updated since they were first proposed) and are shown as red dots in (Figure 7). Results from this study and then summarized in the policy paper [26] showed that about $38 \%$ of the agents within the first 20 minutes after the earthquake occurred could not reach safe zones. Between the areas most exposed to the tsunami, near the casino (Figure 7), and the assembly point, the pedestrian evacuation may take more than $30 \mathrm{~min}$.

Viña's downtown concentrates a large amount of tourists, especially during the summer season. This study showed the high exposure of the population to huge and near-field tsunamis like the 1730 event, and it highlighted the need for establishing vertical evacuation as an effective disaster risk reduction mechanism. Agent-based model results from [31] have been exposed only in scientific conferences. We did not include agent-based models in the projections during these activities. For now on, we only emphasize, through the 3D projections, the need for self-evacuation immediately after shaking if its duration lasts more than $30 \mathrm{~s}$ and if it is strong enough for one to become off balance. We are still exploring how representing agent-based simulations in 3D projections may help with reinforcing the most important message for the general public: be prepared. This information is crucial, and we are working on the ethical concerns on how to address this kind of issue to create awareness 
without generating fear. However, there was a need to open these results to the general public through the policy paper [26].

To date, vertical evacuation is not yet considered as an official alternative to mitigate tsunami risks; therefore, it is important to start presenting this alternative to the decision makers.

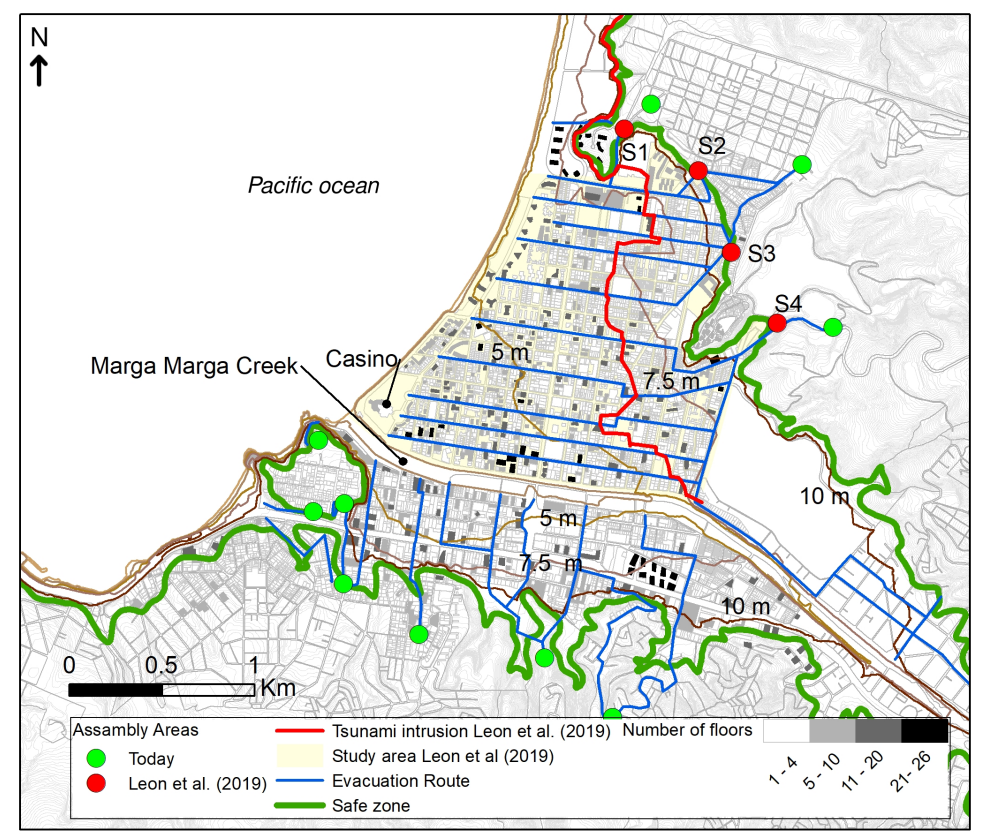

Figure 7. Map of Viña del Mar's downtown. Green dots are the assembly areas in case of a tsunami; green lines demarcate the safe zone; blue lines are the tsunami evacuation routes; these three have been established by the municipality to date. Brown lines are contours every $2.5 \mathrm{~m}$. The gray scale indicates the number of floors of existing buildings. The Población Vergara neighborhood (yellow colored area) maximum tsunami inundation extent [31] is delimited by the red line. Four assembly areas are shown (red dots).

\section{Results}

\subsection{The 1730 Great Valparaíso Earthquake and Tsunami Commemoration}

Two main activities were developed for the 1730 commemoration day. The first one was a simultaneous scientific talk given in schools in Valparaíso and Viña del Mar by university professors and researchers from different institutions, all of them with much experience in different approaches to tsunami research. The schools were randomly selected using only the criteria that they should be located in or near tsunami inundation areas, as shown in Figure 1. Using the same presentation called "Why are we interested in tsunamis?" and oriented toward primary and high school students, the speakers presented the physics of tsunamis, historical tsunamis in the world and Chile, the 1730 Valparaíso event, instructions of what to do in case of an earthquake, and also what scientist do and their challenges in tsunami research. The talks were given at nine schools in Valparaíso and Viña del Mar by nine professors and researchers from different institutions. Nearly 1000 persons were reached by this activity, counting students and teachers. The participant schools are shown in Figure 1 and in Table S1 in the Supplementary Materials.

The second activity was a small scientific exhibition, with stands for ONEMI, SHOA, and CIGIDEN, and also a scientific presentation that explained to local authorities and the general public the physics of tsunamis, the 1730 event, and future risks in the region.

ONEMI brought its seismic simulator vehicle (donated by the Japanese government in 2016), as shown in Figure 3. The vehicle simulated a dining room, and in this case, it moved according to the 2010 Mw 8.8 Maule event. SHOA showed real tide gauge equipment and also exhibited tsunami 
inundation charts (CITSU, in Spanish), which are the official inputs to define the maximum expected flood levels for the main urban and port areas of coastal Chile, in case of a near-field tsunamigenic seismic event. CIGIDEN mounted an exhibition with TsunamiLab and projection mapping of tsunami inundation on the Valparaíso terrain relief mock-up where the 1730 tsunami inundation was projected, as described in Section 3.1 and shown in Figure 4.

Scientific talks were given by researchers of diverse universities, and the aim of the presentations was to explain the general concepts of tsunamis, also emphasizing the importance of scientific research and its connection with decision makers and society at large. While these activities took place at schools in Viña del Mar and Valparaíso, the public exhibition was mounted near La Matriz Church Square, inviting citizens and children to interact with researchers and the different modules. A broad scientific talk (Figure 8) was introduced by experts who have greatly contributed to the study of paleotsunamis and tsunami hazard. In particular, they brought to the community the main aspects of the footprints of the 1730 earthquake and tsunami, as well as putting in context the frequency of other great earthquakes across Chile [1,12,35-38].

At La Matriz Square, there was an exhibition where students and the public could benefit from interactive explanations of the hazard and the risk from state organizations as ONEMI and SHOA and academia (Figure 8). It was estimated that approximately 300 people attended this talk and exhibition. Furthermore, it is relevant to mention that each institution contributed with journalists who interviewed those involved in the planning and the assistants in La Matriz Square. The impact of such activities and the role of the media needs further analysis. However, regarding media coverage, one local and two national newspapers, three expositions on TV shows, and seven websites covered the news, spreading this information and showing the supporting material to thousands of viewers nationwide. The main message of the media was the warning that the 1730 event was huge, and it could happen again. Detailed information about the media coverage is shown in Table S3 (Supplementary Materials).

Finally, ONEMI, Proyecta Memoria Foundation, and CIGIDEN together with academia have run several initiatives that are intended to be extended to a national scale. Furthermore, an important role of the media has been to generate interviews and documentaries that periodically bring up the effects of different recent and historical earthquakes and tsunamis that occurred in Chile and elsewhere. Following the proposed World Tsunami Awareness Day United Nations General Assembly in December, Chile and Japan have implemented binational tsunami drills and shared the outcomes. In fact, the first experience was developed in 2016 in Valparaíso.
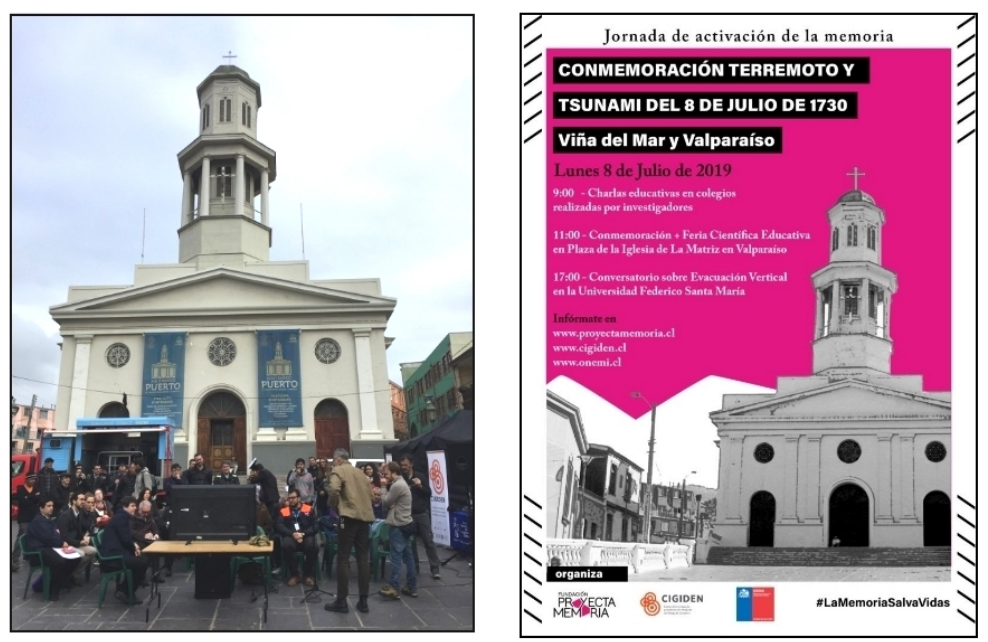

Figure 8. Authorities, students of the Santa Ana school, and the public attending the scientific talks (left panel). Invitation poster of the great 1730 Valparaíso earthquake and tsunami commemoration (right panel). 


\subsection{Launch of the Policy Paper about Vertical Evacuation Measures}

The commemoration and dissemination activities were aligned with the CIGIDEN recommendations associated with vertical evacuation [26] as an alternative to safeguard people's lives from a tsunami. International experiences in Indonesia and Japan show that a feasible way of reducing the potential number of casualties caused by near-field tsunamis in severely exposed areas relies on vertical evacuation.

Taking into account the possibility of facing an earthquake with similar characteristics of the event of 1730, CIGIDEN aimed at gathering the center's ongoing research about tsunamis and evacuation into a policy-oriented guidebook [26]. With this objective, a team of researchers worked out a document addressing this problem in Chile, with an emphasis on the case study of Viña del Mar. The policy paper, called "Vertical evacuation as a measure to mitigate the risk of tsunamis in Chile" [26], includes a description of the current tsunami threat for central Chile and an examination of current evacuation scenarios in Viña del Mar. This led to the description of global examples of vertical evacuation facilities, and the assessment of an improved scenario in Viña del Mar including vertical evacuation buildings, which showed noticeable reduction in potential death rates among the population.

The policy paper was launched on 8 July 2019, the same day the 1730 event occurred, as a closure activity for its commemoration day (Figure 9). The activity was a brief talk of the main ideas developed through the paper. Following the presentation, a scientific-citizen round table was done, including the head of the Instituto de Geografía of the PUCV, the director of the Disaster Risk Reduction and Reconstruction Program of the Minister of Housing and Urban Development (MINVU, in Spanish), the national deputy director of ONEMI, the vice president of the Neighborhood Council of Viña del Mar, and a parliamentarian from the Valparaíso Region. Approximately 100 people attended this event. Regarding media coverage, one local and four national newspapers, four expositions on TV shows, and six websites published articles about the vertical evacuation, highlighting that it was an option to reduce the death toll in the case of large tsunamis. Detailed information about the media coverage is shown in the Supplementary Materials (see Table S3).
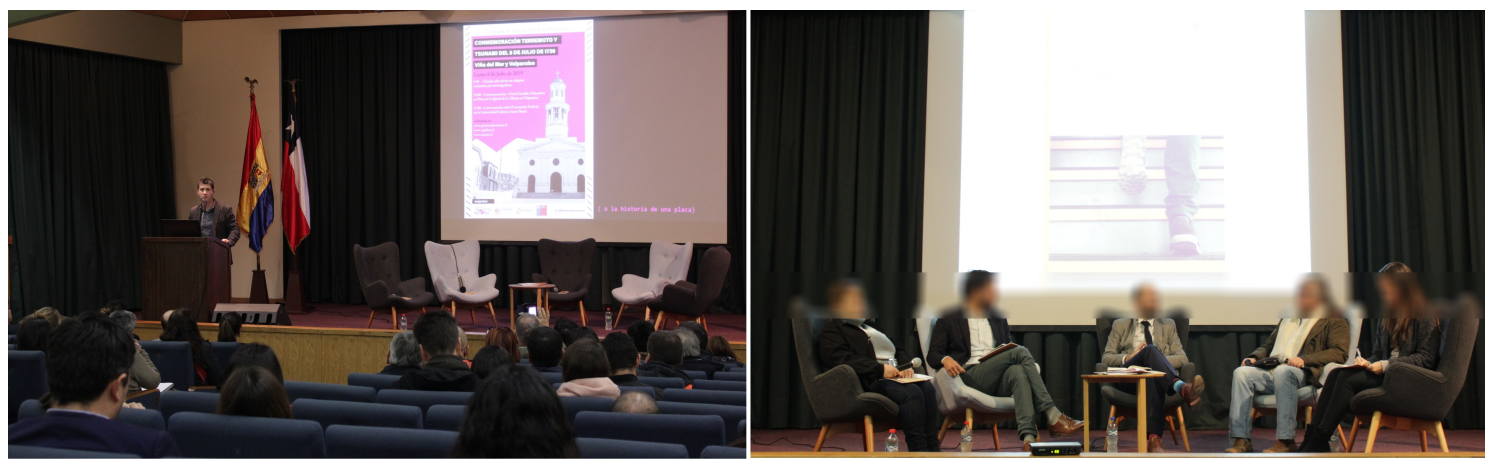

Figure 9. Photos of the round table discussions at UTFSM. Refer to the meeting's introductory video with views of Valparaíso (shown in video S3).

The booklet provides a strong case for the development of vertical evacuation strategies in Chile. It delivers a number of guidelines for implementing these policies, including design, management, structural, and public-engagement aspects, which can be used to both assess existing buildings and project new ones. In line with this, vertical evacuation has been suggested as a tsunami risk mitigation strategy that, if social, political, and juridical consensus is achieved, might lead to a great decrease in the number of human casualties, in case an event like the 1730 one affects the Chilean coast again. Moreover, most of the requirements suggested by CIGIDEN for vertical evacuation structures could be fulfilled by already existing buildings in exposed Chilean cities.

There are two key points that have been under analysis, both from the legal frame and the structural safety of buildings. This implies that the existing legal framework should allow people access to private or governmental buildings, but also it has to be assessed whether the selected 
buildings for vertical evacuation are able to resist the strong shaking and people can be saved. So far, one of the solutions is to work with structural engineers on a case-by-case basis to decide which of those buildings, selected as shelters for vertical evacuation, could withstand strong ground shaking. This approach, however, requires access to each building's portfolio of construction blueprints and technical specifications, which may not be always available.

\section{Final Remarks and Future Perspectives}

Chile is an area prone to mega-earthquakes that trigger large tsunamis. Following the $2010 \mathrm{Mw}$ 8.8 Maule earthquake, the government has invested in different aspects of risk mitigation based on the Sendai framework for risk reduction. However, people's risk perception varies throughout generations, time, and circumstances. Following these guidelines, we are convinced that civil society and organizations can jointly collaborate to comply with the guidelines established to mitigate risk while transferring scientific knowledge to the population.

In order to raise awareness that a major tsunami could affect Valparaíso as happened in 1730, organizations, research centers, and authorities such as Proyecta Memoria, CIGIDEN, ONEMI, CYCLO, UTSFM, and the Valparaíso local government organized a scientific day on 8 July 2019, exactly 289 years after that historical event occurred. One of the main aspects of the commemoration day was to generate scientific information to explain the potential that the Valparaíso region has to host tsunamis with wave heights of about $20 \mathrm{~m}$. People need to make decisions to mitigate risk, guided by authorities, but also their own perception of risk. By providing clear information to the population, including the associated uncertainties (what we know and do not know), the expected reaction during such events will mitigate the risk. This is especially true for tsunami earthquakes, which may not generate strong ground shaking, but could be accompanied by devastating tsunamis.

The second approach was to discuss the possibilities of vertical evacuation in a touristic city that has such a transient population and incipient development along the seaside. This is an open debate, and some facts have been discussed; yet, there is a need for consensus that has to come from the authorities' perspective.

Finally, with these outreach activities, it is intended to close the bridge between academia, authorities, and the population. It is expected that their replication every year, with diverse activities for all the population, including material that can be addressed to handicapped people, will contribute to increasing awareness of the population.

\section{Data and Resources}

Bathymetry: GEBCO, The General Bathymetric Chart of the Oceans www.gebco.net ALOS: https:/ / www.eorc.jaxa.jp/ALOS/en/aw3d30/index.htm, and from SHOA via the CENDHOC program: http://www.shoa.cl/n_cendhoc/

Tsunami inundation map CITSU from SHOA: http:/ / www.shoa.cl/php/citsu.php

Seismic source: the input model for numerical simulation is based on [1].

Supplementary Materials: The following are available online at http:/ /www.mdpi.com/2076-3263/10/6/246/s1, Table S1: Summary of schools where scientific talks were given and the instructors; Table S2: Summary of past activities; Table S3: Summary of the news that covered the 8 July 2019 commemoration day; Video S1: Tsunami simulations along Viña del Mar; Video S2: Tsunami simulations along Valparaíso; Video S3: This video shows Valparaíso surroundings from above.

Author Contributions: Conceptualization: N.Z., A.G., V.O., J.L., and P.W.; funding acquisition: V.O. and R.C.; investigation: N.Z., A.G., and J.L. methodology: A.G. and J.L.; project administration: R.C., S.V., and P.C.; resources, J.L., A.U., M.C. (Matías Carvajal), M.C. (Marco Cisternas), C.K., J.G., and C.B.; software: J.G., S.P., and C.B.; supervision: R.C.; visualization: N.Z. and A.G.; writing, original draft: N.Z., A.G., V.O., and J.L.; writing, review and editing: N.Z., A.G., A.U., M.C. (Matías Carvajal), M.C. (Marco Cisternas), P.C., P.W., and R.C. All authors read and agreed to the published version of the manuscript.

Funding: This research received no external funding rather than the express below. 
Acknowledgments: The results presented in this study were the progressive efforts of many people. In particular, we acknowledge Fundación Proyecta Memoria, the Research Center for Integrated Disaster Risk Management (CIGIDEN), ANID/FONDAP/15110017, Municipalidad de Valparaíso, Carabineros, Universidad Técnica Federico Santa María, Pontificia Universidad Católica de Valparaíso, and CYCLO Millennium Nucleus: The Seismic Cycle Along Subduction Zones (Grant NC160025). M. Cisternas and M. Carvajal acknowledges the support of the FONDECYT No. 1190258. J. León acknowledges the support of ANID/Fondecyt No. 11170024. P.A. Catalán was partially funded by ANID PIA/APOYO AFB180002 and ANID/FONDAP/15110017. Special acknowledgment is given to the collaboration of D. Gutiérrez, R. Aránguiz, M. Contreras, M. Reyes, the Valparaíso Police Department, the municipality, the professors from each school, and the UTFSM students: A. Cabrera, P. Brito, E. Opazo, F. Soto. Also, H. Basoalto, and P. Mora from Proyecta Memoria; for participating in the round table: B. Paul, the national person in charge of Disaster Risk Reduction and Reconstruction of the MINVU; J. González, vice president of the Communal Union of Juntas de Vecinos de Viña del Mar; J. Brito, deputy from the Valparaíso Region and from the Democratic Revolution party; C. Mena, national deputy director of ONEMI; and L. Álvarez, director of the Institute of Geography of the Pontificia Universidad Católica de Valparaíso. J. Galaz, S. Pereira, and C. Bertin developed the TsunamiLab pool, funded by CORFO10CEII-9157 Inria Chile. Most figures were made with Global Mapping Tool. We thank the Guest Editor M. Charalampakis, A. Wu, and two anonymous reviewers for valuable suggestions.

Conflicts of Interest: The authors declare no conflict of interest.

\section{Abbreviations}

$\begin{array}{ll}\text { ALOS } & \text { Global Digital Surface Model “ALOS World 3D-30m (AW3D30)” } \\ \text { CENDHOC } & \text { Centro Nacional de Datos Hidrográficos y Oceanográficos de Chile. } \\ \text { CIGIDEN } & \text { Research Center for Integrated Disaster Risk Management, ANID/FONDAP/15110017 } \\ \text { CITSU } & \text { Cartas de Inundación por Tsunami } \\ \text { CYCLO } & \text { Millennium Nucleus: The Seismic Cycle Along Subduction Zones } \\ \text { INE } & \text { Instituto Nacional de Estadísticas } \\ \text { MINVU } & \text { Ministerio de Vivienda y Urbanismo } \\ \text { ONEMI } & \text { Oficina Nacional de Emergencia del Ministerio del Interior } \\ \text { SHOA } & \text { Servicio Hidrográfico y Oceanográfico de la Armada de Chile } \\ \text { PUC } & \text { Pontificia Universidad Católica de Chile } \\ \text { PUCV } & \text { Pontificia Universidad Católica de Valparaíso } \\ \text { UCN } & \text { Universidad Católica del Norte } \\ \text { UDEC } & \text { Universidad de Concepción } \\ \text { UPLA } & \text { Universidad de Playa Ancha } \\ \text { USCS } & \text { Universidad de la Santísima Concepción } \\ \text { UV } & \text { Universidad de Valparaíso } \\ \text { UTFSM } & \text { Universidad Técnica Federico Santa María }\end{array}$

\section{References}

1. Carvajal, M.; Cisternas, M.; Catalán, P.A. Source of the 1730 Chilean earthquake from historical records: Implications for the future tsunami hazard on the coast of Metropolitan Chile. J. Geophys. Res. Solid Earth 2017, 122, 3648-3660. [CrossRef]

2. NCEI/WDS. National Geophysical Data Center, World Data Service. Global Historical Tsunami Database. National Geophysical Data Center; NOAA: Silver Spring, MD, USA, 2020. [CrossRef]

3. SHOA. Carta de Inundación por Tsunami (CITSU) de Valparaíso y Viña del Mar; Servicio Hidrográfico y Oceanográfico de la Armada de Chile: Valparaíso, Chile, 2012.

4. Udías, A.; Madariaga, R.; Buforn, E.; Muñoz, D.; Ros, M. The large Chilean historical earthquakes of 1647, 1657, 1730, and 1751 from contemporary documents. Bull. Seismol. Soc. Am. 2012, 102, 1639-1653. [CrossRef]

5. USGS. USGS ComCat Catalog; United States Geological Survey, 2017. Available online: https://earthquake. usgs.gov/earthquakes/search/ (accessed on 20 January 2017).

6. Tsuji, Y. Catalog of Distant Tsunamis Reaching Japan from Chile and Peru. Rep. Tsunami Eng. 2013, 30, 61-68.

7. Montessus de Ballore, F. Historia Sísmica de los Andes Meridionales al sur del Paralelo XVI, Cuarta Parte; Imprenta Cervantes: Santiago, Chile, 1914.

8. Lomnitz, C. Major earthquakes of Chile: A historical survey, 1535-1960. Seismol. Res. Lett. 2004, 75, 368-378. [CrossRef] 
9. GoogleMaps. Photo Gallery. 2020. Available online: https://www.google.cl/maps/@-33.0361079,-71. 6312619,3a,75y,211.35h,89.37t/ data=!3m6!1e1!3m4!1spKyyo82Y5IqrxTZrYEKGBQ!2e0!7i13312!8i6656 (accessed on 15 April 2020).

10. Arias, J.P.; Bronfman, N.C.; Cisternas, P.C.; Repetto, P.B. Hazard proximity and risk perception of tsunamis in coastal cities: Are people able to identify their risk? PLoS ONE 2017, 12, e0186455. [CrossRef]

11. Bronfman, N.C.; Cisternas, P.C.; López-Vázquez, E.; Cifuentes, L.A. Trust and risk perception of natural hazards: Implications for risk preparedness in Chile. Nat. Hazards 2016, 81, 307-327. [CrossRef]

12. Carvajal, M.; Cisternas, M.; Gubler, A.; Catalán, P.A.; Winckler, P.; Wesson, R.L. Reexamination of the magnitudes for the 1906 and 1922 Chilean earthquakes using Japanese tsunami amplitudes: Implications for source depth constraints. J. Geophys. Res. Solid Earth 2017, 122, 4-17. [CrossRef]

13. Cortés, P.; Catalán, P.A.; Aránguiz, R.; Bellotti, G. Tsunami and shelf resonance on the northern Chile coast. J. Geophys. Res. Oceans 2017, 122, 7364-7379. [CrossRef]

14. Aránguiz, R.; Catalán, P.A.; Cecioni, C.; Bellotti, G.; Henriquez, P.; González, J. Tsunami Resonance and Spatial Pattern of Natural Oscillation Modes With Multiple Resonators. J. Geophys. Res. Oceans 2019, 124, 7797-7816. [CrossRef]

15. Kanamori, H. Mechanism of tsunami earthquakes. Phys. Earth Planet. Inter. 1972, 6, 346-359. [CrossRef]

16. Hill, E.M.; Borrero, J.C.; Huang, Z.; Qiu, Q.; Banerjee, P.; Natawidjaja, D.H.; Elosegui, P.; Fritz, H.M.; Suwargadi, B.W.; Pranantyo, I.R.; et al. The 2010 M w 7.8 Mentawai earthquake: Very shallow source of a rare tsunami earthquake determined from tsunami field survey and near-field GPS data. J. Geophys. Res. 2012, 117, B06402. [CrossRef]

17. Kanamori, H.; Kikuchi, M. The 1992 Nicaragua earthquake: A slow tsunami earthquake associated with subducted sediments. Nature 1993, 361, 714-716. [CrossRef]

18. Suppasri, A.; Shuto, N.; Imamura, F.; Koshimura, S.; Mas, E.; Yalciner, A.C. Lessons Learned from the 2011 Great East Japan Tsunami: Performance of Tsunami Countermeasures, Coastal Buildings, and Tsunami Evacuation in Japan. Pure Appl. Geophys. 2013, 170, 993-1018. [CrossRef]

19. Kânoğlu, U.; Titov, V.; Bernard, E.; Synolakis, C. Tsunamis: Bridging science, engineering and society. Philos. Trans. R. Soc. Math. Phys. Eng. Sci. 2015, 373, 20140369. [CrossRef]

20. Koichi, S.; Rajib, S. Proactive co-learning: A new paradigm in disaster education. Disaster Prev. Manag. Int. J. 2008, 17, 183-198. [CrossRef]

21. Dengler, L. The role of education in the National Tsunami Hazard Mitigation Program. Nat. Hazards 2005, 35, 141-153. [CrossRef]

22. Kitagawa, K. Co-constructing a narrative of 'never give up' in preparing for a mega-tsunami: An exemplar of 'all-of-society engagement'? Geosciences 2019, 9, 486. [CrossRef]

23. ONEMI. Guía para la Planificación y Ejecución de Simulacros de Terremotos y Tsunamis; Technical Report; Ministerio del Interior y Seguridad Pública: Santiago, Chile, 2014.

24. Catalán, P.; Gubler, A.; Cañas, J.; Zuñiga, C.; Zelaya, C.; Pizarro Baeza, L.; Valdés, C.; Mena, R.; Toledo, E.; Cienfuegos, R. Design and operational implementation of the integrated tsunami forecast and warning system in Chile (SIPAT). Coast. Eng. J. 2020, 1-16. [CrossRef]

25. Martínez, C.; Cienfuegos, R.; Inzunza, S.; Urrutia, A.; Guerrero, N. Worst-case tsunami scenario in Cartagena Bay, central Chile: Challenges for coastal risk management. Ocean Coast. Manag. 2020, 185, 105060. [CrossRef]

26. León, J.; Zamora, N.; Castro, S.; Jünemann, R.; Gubler, A.; Cienfuegos, R. Evacuación Vertical como Medida de Mitigación del Riesgo de Tsunamis en Chile. Series Policiy Paper, Santiago, Chile; Technical Report; National Research Center for Integrated Natural Disaster Management (CIGIDEN), Santiago, Chile, 2019. Available online: https: / / www.cigiden.cl/wp-content/uploads/2019/07/PPCIGIDEN\{_\}EvacVert\{_\}digital.pdf (accessed on 10 April 2020).

27. Berger, M.J.; George, D.L.; LeVeque, R.J.; Mandli, K.T. The GeoClaw software for depth-averaged flows with adaptive refinement. Adv. Water Resour. 2011, 34, 1195-1206. [CrossRef]

28. Leveque, R.J.; George, D.L.; Berger, M.J. Tsunami modelling with adaptively refined finite volume methods. Acta Numer. 2011, 20, 211-289. [CrossRef]

29. INE. Censo de Población y Vivienda 2017; Instituto Nacional de Estadísticas: Santiago, Chile, 2017.

30. INE. Encuesta Mensual de Alojamiento Turístico, Febrero, Región de Valparaíso, 2019; Edicion N49; Instituto Nacional de Estadísticas: Santiago, Chile, 2019. 
31. León, J.; Mokrani, C.; Catalán, P.; Cienfuegos, R.; Femenías, C. Examining the role of urban form in supporting rapid and safe tsunami evacuations: A multi-scalar analysis in Viña del Mar, Chile. Procedia Eng. 2018, 212, 629-636. [CrossRef]

32. Arikawa, T. Development of High Precision Tsunami Simulation Based on a Hierarchical Intelligent Simulation. In Proceedings of the 34th JSST Annual Conference International Conference on Simulation Technology, Toyama, Japan, 12-14 October 2015.

33. Tomita, T.; Honda, K.; Kakinuma, T. Application of storm surge and tsunami simulator in ocean and coastal areas (STOC) to tsunami analysis. Jt. Panel Conf. US-Jpn. Coop. Program Nat. Resour. 2006, 38, 109-115.

34. SECTRA. Encuesta de Origen-Destino de Viajes Gran Valparaíso. Ministerio de Obras Públicas, Transportes y Telecomunicaciones; Technical Report; Secretará de Planificación de Transporte, 2016. Available online: http:/ / www.sectra.gob.cl/encuestas_movilidad/encuestas_movilidad.htm (accessed on 15 March 2020).

35. Cisternas, M.; Atwater, B.F.; Torrejón, F.; Sawai, Y.; Machuca, G.; Lagos, M.; Eipert, A.; Youlton, C.; Salgado, I.; Kamataki, T.; et al. Predecessors of the giant 1960 Chile earthquake. Nature 2005, 437, 404-407. [CrossRef] [PubMed]

36. Cisternas, M.; Torrejón, F.; Gorigoitia, N. Amending and complicating Chile's seismic catalog with the Santiago earthquake of 7 August 1580. J. S. Am. Earth Sci. 2012, 33, 102-109. [CrossRef]

37. Dura, T.; Cisternas, M.; Horton, B.P.; Ely, L.L.; Nelson, A.R.; Wesson, R.L.; Pilarczyk, J.E. Coastal evidence for Holocene subduction-zone earthquakes and tsunamis in central Chile. Quat. Sci. Rev. 2015, 113, 93-111. [CrossRef]

38. Wessel, P.; Luis, J.F.; Uieda, L.; Scharroo, R.; Wobbe, F.; Smith, W.H.F.; Tian, D. The Generic Mapping Tools Version 6. Geochem. Geophys. Geosyst. 2019, 20, 5556-5564. [CrossRef]

(C) 2020 by the authors. Licensee MDPI, Basel, Switzerland. This article is an open access article distributed under the terms and conditions of the Creative Commons Attribution (CC BY) license (http:/ / creativecommons.org/licenses/by/4.0/). 